\title{
Penanaman Karakter Bangsa Melalui Ekstrakulikuler Kepramukaan di SMP/MTS Se-Kecamatan Mungkid
}

\section{Isni Yun Lasi, Arif Purnomo, Fredy Hermanto}

Social Science Education Department, Faculty of Social Science, Universitas Negeri Semarang, Indonesia

\begin{tabular}{l}
\hline Info Artikel \\
\hline Sejarah Artikel: \\
Disubmit \\
Direvisi \\
Diterima \\
\hline Keywords: \\
naation character, \\
extracurricular, scouting
\end{tabular}

extracurricular, scouting

\begin{abstract}
Abstrak
Karakter bangsa Indonesia yang mulai pudar memerlukan sebuah upaya untuk mengatasinya. Ekstrakurikuler Kepramukaan merupakan salah satu kegiatan ekstrakurikuler yang menjadi upaya pendidikan karakter. Penelitian ini bertujuan untuk mengetahui (1) nilai karakter bangsa yang ditanamkan melalui ekstrakurikuler kepramukaan di SMP/MTs se-Kecamatan Mungkid; (2) upaya penanaman nilai karakter bangsa melalui ekstrakurikuler kepramukaan di SMP/MTs seKecamatan Mungkid; (3) faktor yang mendukung dan menghambat penanaman nilai karakter bangsa melalui ekstrakurikuler kepramukaan di SMP/MTs se-Kecamatan Mungkid. Metode penelitian yaitu metode penelitian kualitatif deskriptif. Teknik pengumpulan data yang digunakan adalah observasi, wawancara dan dokumentasi. Hasil penelitian menunjukan nilai karakter bangsa yang ditanamkan melalui ekstrakurikuler kepramukaan di SMP/MTs se-Kecamatan Mungkid adalah religius, disiplin, kreatif, mandiri, demokratis, cinta tanah air, dan menghargai prestasi yang diupayakan melaui perencanaan kegiatan, lomba-lomba kepramukaan dan uji SKU dan SKK. Adapun faktor pendorong dan penghambat antara lain faktor internal (motivasi peserta didik) dan faktor eksternal (pembina atau pelatih, keluarga, dan sekolah).
\end{abstract}

\begin{abstract}
The character of the Indonesian nation that began to fade requires an attempt to overcome. Scouting is one of the extracurricular activities that became the character education effort. This study aimed to (1) know the value of the character of the nation that is planted through scouting in SMP / MTs in Mungkidregency, (2) to know the effort to cultivate the value of nation character through scouting in SMP / MTs in Mungkidregency; (3) to know the factors that support and obstruct the cultivation of nation character value through scouting in SMP / MTs in Mungkidregency. The research method usedwas descriptive qualitative research method. Data collection techniques used were observation, interview and documentation. The result of this research showed the value of the character of the nation that is planted through scouting in SMP / MTs in Mungkid regency were religious, discipline, creative, independent, democratic, love the homeland, and appreciate the achievements pursued through the activity planning, scouting contest and SKU test and SKK. The driving and inhibiting factors include internal factors (motivation of learners) and external factors (coach or coach, family, and school).
\end{abstract}

(C) 2019 Universitas Negeri Semarang

\footnotetext{
Alamat korespondensi:

Gedung C1 Lantai 1 Program Studi Pendidikan IPS FIS UNNES

E-ISSN 2685-4929

Kampus Sekaran, Gunungpati, Semarang, 50229

E-mail: jurnalharmonipips@gmail.com
} 


\section{PENDAHULUAN}

Salah satu tujuan pendidikan nasional Indonesia yang tercantum dalam Pembukaan Undang-Undang Dasar 1945 ialah mencerdaskan kehidupan bangsa. Namun, kecerdasan tersebut tidak hanya dari aspek kognitif (pengetahuan) saja, akan tetapi mencakup kecerdasan afektif dan spiritualnya. Pendidikan menjadi salah satu upaya dalam mencapai tujuan tersebut, baik itu pendidikan formal maupun nonformal.

Menurut Mulyasa (2013:7) pendidikan karakter dalam kurikulum 2013 bertujuan untuk meningkatkan mutu proses dan hasil pendidikan, yang mengarah pada pembentukan budi pekerti dan akhlak mulia peserta didik secara utuh, terpadu, dan seimbang sesuai dengan standar kompetensi lulusan pada setiap satuan pendidikan.

Mengapa perlu pendidikan karakter secara lebih tegas diterapakan tidak hanya fokus pada aspek kompetensinya saja, karena dewasa ini perlu adanya pembekalan terhadap peserta didik agar mampu menghadapi tantangan zaman serta perkembangan teknologi yang terus berkembang. Khususnya bagi remaja dan generasi muda, seseorang yang memasuki usia remaja akan dihadapkan dengan tantangan dan rasa ingin tahu yang tinggi.

Pemberitaan mengenai kriminalitas dan penyimpangan sosial seperti perampokan, tawuran pelajar, pemerkosaan, serta tindakan bullying sering kira dengar dari televisi, surat kabar maupun media sosial. Hal ini menujukan semakin lunturnya jati diri bangsa Indonesia, khususnya di kalangan remaja dan pelajar.

Permasalahan karakter bangsa yang mulai kehilangan jati diri tersebut memerlukan sebuah penanganan dan tindakan. Maka perlulah pendidikan karakter bangsa, yang salah satu caranya ialah melalui ekstrakurikuler. Ekstrakurikuler kepramukaan merupakan salah satu ekstrakurikuler yang dapat menjadi alternatif dalam pembentukan karakter bangsa

\section{METODE PENELITIAN}

Metode penelitian yang digunakan adalah metode penelitian kualitatif deskriptif. Penelitian dilakukan pada tiga sekolah tingkat menengah pertama (SMP) di Kecamatan Mungkid, yakni SMP Negerin 1 Mungkid, MTs Pondok Pabelan, dan MTs Ma`arif NU Roudlotul Mubtadien Blondo. Sumber data diperoleh dari data primer berupa informasi utama yaitu Kepala Sekolah (Kamabigus), Pembina Pramuka dan Anggota Pramuka (peserta didik). Serta data sekunder berupa dokumentadi foto dan dokumen-dokumen lain yang dianggap relevan dengan penelitian ini. Teknik analisis data adalah observasi, wawancara, dan dokumentasi. Keabsahan data di uji dengan triangulasi sumber dan triangulasi teknik. Analisis data yaitu dengan pengumpulan data, reduksi data, penyajian data, pengambilan dan simpulan/verifikasi.

\section{PEMBAHASAN}

\section{Nilai Karakter Bangsa yang Ditanamkan melalui Ekstrakurikuler Kepramukan di SMP/MTs Se-Kecamatan Mungkid}

\section{Religius}

Berdasarkan pengamatan yang peneliti lakukan pada tiga sekolah tersebut, peneliti menemukan bahwa doa selalu disisipkan dalam setiap upacara maupun apel berlangsung. Kemudian selain melalui doa, perilaku peserta didik yang mencerminkan sikap religius ialah mengucakpan salam saat akan memulai kegiatan dan menutup kegiatan, dan juga melalui kegiatan sholat ashar berjamaah.

Karakter religius merupakan karakter yang tercermin dalam salah satu kode kehormatan seorang pramuka. Sebagaimana tercantum dalam Undang-Undang Nomor 12 Tahun 2010 tentang Gerakan Pramuka pasal 6. Kode kehormatan merupakan janji komitmen diri serta ketentuan moral seorang pramuka. Kode kehormatan terdiri atas Satya Pramuka (Tri Satya) dan Dharma Pramuka (Dasa Dharma). Adapun bunyi Dasa Dharma yang 
pertama ialah Taqwa kepada Tuhan Yang Maha Esa.

\section{Disiplin}

Karakter disiplin peserta didik dapat terlihat pada kegiatan baris berbaris, upacara maupun apel serta dapat terlihat dari pakaian seragam yang dikenakan peserta didik dalam kegiatan ekstrakurikuler kepramukaan. Selain itu karakter disiplin juga dapat di tanamkan melalui ketepantan waktu dalam berkegiatan.

Karakter disipin merupakan karakter yang termuat pada salah satu Dasa Dharma Pramuka. Dasa Dharma merupakan kode kehormatan seorang pramuka. Berdasarkan Undang-Undang Nomor 12 Tahun 2010 tentang Gerakan Pramuka pada Pasal 6, disebutkan bahwa kode kehormatan terdiri atas Satya Pramuka (Tri Satya) dan Dharma Pramuka (Dasa Dharma Pramuka). Karakter disiplin termuat pada Dasa Dharma ke delapan yang berbunyi disiplin, berani dan setia.

\section{Kreatif}

Berdasarkan pengamatan yang peneliti lakukan serta wawancara di tiga sekolah, dapat dilihat bahwa kreatifitas peserta didik muncul melalui kegiatan keterampilan. Peserta didik akan mengikuti kegiatan yang telah dijadwalkan, dan mereka akan mengembangkan kreatifitas melalui hal tersebut.

Karakter kreatif atau terampil merupakan karakter yang terdapat dalam kode kehormatan seorang pramuka. Sebagaimana tercantum dalam Undang-Undang No 12 Tahun 2010 tentang Gerakan Pramuka. Karakter tersebut termuat dalam kode kehormatan pramuka yakni Dasa Dharma ke enam yakni rajin,terampil dan gembira.

\section{Mandiri}

Karakter mandiri peserta didik dapat dilihat melalui kegiatan-kegiatan kepramukaan, yang mana mereka harus menjadi pribadi yang mandiri, tidak seperti di lingkungan rumah yang semua bisa di penuhi dengan mudah. Melalui ekstrakurikuler kepramukaan peserta didik dilatih untuk mandiri, seperti saat mengikuti perkemahan dan lomba-lomba, peserta didik harus beraktifitas jauh dari orang tua dan dituntut untuk saling bekerja sama antar sesama anggota.

Karakter mandiri merupakan karakter yang ditanamkan pada kegiatan ekstrakurikuler kepramukaan sebagaimana terdapat dalam Kemendikbud tahun 2010 tentang Panduan Pendidikan Karakter di Sekolah Menengah Pertama, dijabarkan bahwa kepramukaan merupakan salah satu bentuk Pembinaan kesiswaan dan melalui kepramukaan, nilai-nilai karakter yang dapat ditanamkan antara lain: demokratis, percaya diri, patuh pada aturanaturan sosial, menghargai keberagaman, mandiri, bekerja keras, disiplin dan bertanggung jawab.

\section{Demokratis}

Karakter demokratis pada peserta didik terlihat pada kegiatan peserta didik yang turut terlibat dalam perencanaan kegiatan ekstrakurikuler kepramukaan di masing-masing sekolah. Tentunya setiap sekolah memiliki cara yang berbeda dalam melibatkan peserta didik dalam kegiatan. Melibatkan peserta didik dalam kegiatan dapat menjadi cara sekaligus contoh bagi penanaman sikap demokratis, sikap yang menghargai pendapat orang lain. Menganggap bahwa orang lain memiliki hak yang sama, memiliki pendapat serta pemikiran yang selayaknya diberikan kesempatan untuk di salurkan. Hal tersebut dapat diterapkan oleh peserta didik dalam kehidupan sehari-hari, yakni bermusyawarah dalam kelompokkelompok kecil guna membahas kegiatan yang akan dilakukan.

Karakter demokratis merupakan karakter yang ditanamkan pada kegiatan ekstrakurikuler kepramukaan sebagaimana terdapat dalam Kemendikbud tahun 2010 tentang Panduan Pendidikan Karakter di Sekolah Menengah Pertama, dijabarkan bahwa kepramukaan merupakan salah satu bentuk Pembinaan kesiswaan dan melalui kepramukaan, nilai-nilai karakter yang dapat ditanamkan antara lain: demokratis, percaya diri, patuh pada aturanaturan sosial, menghargai keberagaman, mandiri, bekerja keras, disiplin dan bertanggung 
jawab. Selain itu karakter demokratis juga tercermin pada Kode Kehormatan seorang pramuka, sebagaimana tercantum dalam Undang-Undang Nomor 12 Tahun 2010 tentang Gerakan Pramuka, pada Dasa Dharma ke empat tertulis patuh dan suka bermusyawarah. Musyawarah merupakan kegiatan demokratis yang dilakukan oleh peserta didik dalam perencanaan kegiatan di SMP/MTs seKecamatan Mungkid.

\section{Cinta Tanah Air}

Upaya penanaman karakter cinta tanah air dapat dilihat dari kegiatan upacara ataupun apel saat pembukaan maupun penutupan kegiatan ekstrakurikuler kepramukaan. Susunan upacara ataupun apel didalamnya terdapat penghormatan kepada bendera merah putih yang menjadi bendera kebangsaan Indonesia. selain itu terdapat pengucapan Tri Satya yang menjadi janji seorang anggota pramuka.

Karakter cinta tanah air tercermin pada kegiatan-kegiatan yang dilaksanakan di SMP/MTs se-Kecamatan Mungkid sebagaimana tercantum dalam buku Kursus Pembina Pramuka Mahir Timgkat Dasar, halaman 21 yang diterbitkan oleh Kwartir Nasianal Gerakan Pramuka disebutkan bahwa salah satu Prinsip Dasar Kepramukaan adalah peduli terhadap bangsa, negara, sesama manusia dan alam serta isinya. Cinta tanah air juga terdapat dalam kode kehormatan seorang pramuka yang termuat dalam Undang-Undang Nomor 12 Tahun 2010 tentang Gerakan Pramuka. Yakni pada Dasa Dharma Pramuka kedua, yaitu cinta alam dan kasih sayang sesama manusia.

\section{Menghargai Prestasi}

Wujud menghargai prestasi dapat dilihat pada pengumuman kejuaraan yang di lakukan oleh pihak sekolah. Peserta didik akan merasa mendapat dorongan apresiasi serta semangat, bahwa pihak sekolah selalu mendukung mereka guna mendapat prestasi setinggi-tingginya dalam ekstrakurikuler kepramukaan.

Menghargai prestasi merupakan karakter yang ditunjukan oleh seorang Pembina pramuka dalam membina pasukan penggalang. Sebagaimana tercantum dalam buku Kursus Pembina Pramuka Mahir Tingkat Dasar yang menyebutkan bahwa Dewan Kehormatan Penggalang terdiri atas Pimpinan Regu Utama (Pratama), para Pemimpin Regu, Pembina, dan para Pembantu Pembina memiliki tugas untuk menentukan Pelantikan, pemberian TKK tanda penghargaan dan lainnya kepada Pramuka Penggalang yang berjasa atau berprestasi. Hal ini senada dengan yang terjadi pada kegiatan ekstrakurikuler kepramukaan di SMP/MTs seKecamatan Mungkid.

\section{Upaya Penanaman Karakter Bangsa melalui Ekstrakurikuler Kepramukaan di SMP/MTs Se-Kecamatan Mungkid}

\section{Perencanaan Kegiatan}

Perencanaan kegiatan yang dapat menjadi upaya menumbuhkan karakter bangsa peserta didik ialah perencanaan kegiatan yang dilakukan oleh peserta didik sendiri. Perencanaan tersebut dilaksanakan guna membahas agenda latihan rutin setiap minggu. Tentu saja pada pelaksanaanya berbeda antar satu sekolah dengan sekolah lain yang menjadi lokasi penelitian. Namun pada dasarnya sama, semua membutuhkan kreatifitas, tanggung jawab, keberanian untuk mengambil keputusan, serta kekompakan antar anggota. Peserta didik akan belajar dan dilatih untuk memiliki karakter mandiri, demokratis, menghargai prestasi, disiplin, serta cinta terhadap tanah airnya.

\section{Lomba Kepramukaan}

Lomba kepramukaan merupakan salah satu upaya yang dilakukan oleh pihak sekolah dalam menanamkan karakter bangsa kepada peserta didik. Kompetisi yang dilakukan dapat menjadi sebuah dorongan yang kuat untuk dapat merubah karakter peserta didik. Terlebih bagi usia pramuka penggalang yang merupakan usia remaja. Masa remaja yang membuat rasa ingin tahu bertambah tinggi, serta ingin mencoba hal-hal yang baru. Berdasarkan wawancara yang peneliti lakukan pada peserta didik beberapa mengaku kepercayaan diri 
meningkat karena tertantang untuk mengikuti lomba kepramukaan.

\section{Uji SKU dan SKK}

SKU (Syarat Kecakapan Khusus) merupakan syarat kecakapan yang harus dimiliki oleh peserta didik. SKK (Syarat Kecakapan Khusus) merupakan syarat kecakapan pada bidang tertentu berdasarkan pilihan pribadi dalam pengembangan minat dan bakat peserta didik. Uji SKU dan SKK atau penilaian SKU dan SKK merupakan ujian yang harus dilewati seorang peserta didik untuk memperoleh TKU (Tanda Kecakapan Umum) dan TKK (Tanda Kecakapan Khusus).

SMP/MTs di Kecamatan Mungkid melaksanakan uji SKU dan SKK dengan berbagai metode yang berbeda pada setiap sekolah. Hal ini menunjukan keselarasan dengan aturan yang ada tentang pelaksanaan ekstrakurikuler kepramukaan. Yakni pendidikan kepramukaan dilaksanankan melalui kurikulum pendidikan kepramukaan yang terdiri kurikulum umum yang disebut dengan Syarat Kecakapan Umum (SKU) dan kurikulum khusus yang disebut Syarat Kecakapan Khusus (SKK). SKU diarahan untuk mengembangkan lima ranah kecerdasan peserta didik meliputi rasa spiritual, emosional, sosial, intelektual dan fisik. Indikator hasil pendidikannya berupa Tanda Kecakapan umum (TKU) dan Tanda Kecakapan Khusu (TKK) yang dipasang pada pakaian seragam pramuka peserta didik (Direktorat Pembinaan Sekolah Menengah Pertama, 2015:23).

\section{SIMPULAN}

\section{Simpulan}

Berdasarkan hasil penelitian dan pembahasan yang telah dipaparkan, maka kesimpulan yang dapat diambil ialah sebagai berikut:

1. Nilai karakter bangsa yang ditanamkan kepada peserta didik melalui ekstrakurikuler kepramukaan di SMP/MTs se-Kecamatan Mungkid diantaranya ialah karakter religius, disiplin, kreatif, mandiri, demokratis, cinta tanah air, dan menghargai prestasi.

2. Upaya-upaya yang dilakukan untuk menanamkan nilai karakter bangsa kepada peserta didik ialah melalui berbagi kegiatan di ekstrakurikuler kepramukaan, diantaranya ialah perencanaan kegiatan, kemudian adanya lomba-lomba kepramukaan baik yang sifatnya berjenjang maupun lomba-lomba yang diadakan oleh instansi tertentu, dan terakhir melalui uji SKU dan SKK yang dikemas berbeda-beda pada setiap sekolah yang menjadi lokasi penelitian di SMP/MTs se-Kecamatan Mungkid.

3. Adapun faktor pendorong serta penghambat upaya penanaman nilai karakter bangsa kepada peserta didik di SMP/MTs se-Kecamatan Mungkid yakni berupa faktor internal dan faktor eksternal. Faktor internal ialah berasal dari dalam diri peserta didik sendiri yang berupa motivasi, sementara faktor eksternal diantaranya ialah berasal dari pembina atau pelatih, keluarga, sekolah atau madrasah serta tersedianya sarana serta prasarana yang dimiliki oleh sekolah atau madrasah.

\section{Saran}

Berdasarkan hasil penelitian dan simpulan diatas, maka dapat disampaikan saran sebagai berikut:

1. Bagi Pembina, hendaknya meningkatkan kerjasama dengan pelatih dan sekolah agar dapat lebih maksimal dalam mengembangkan potensi yang dimiliki peserta didik di bidang kepramukaan.

2. Bagi sekolah, yaitu : Hendaknya semakin meningkatkan pengelolaan sarana dan prasarana penunjang kegiatan ekstrakurikuler kepramukaan seperti melakukan inventarisasi perlengkapan dan pengecekkan peralatan secara berkala; Memberikan dorongan moral kepada peserta didik dan pembina atas prestasi yang telah dicapai, sehingga semakin memupuk rasa percaya diri dan meningkatkan semangat berkompetisi. 


\section{DAFTAR PUSTAKA}

Kementerian Pendidikan Nasional Tahun 2010 tentang Panduan Pendidikan Karakter di Sekolah Menengah Pertama.

Kementrian Pendidikan dan Kebudayaan; Direktorat Jenderal Pendidikan Dasar dan Menegah; Direktorat Pembinaan Sekolah Menengah Pertama. 2015. Panduan Pelaksanaan Kepramukaan Sekolah Menengah Pertama. Jakarta: SAI GLOBAL.

Kwartir Nasional. 2014. Kursus Pembina Pramuka Mahir Tingkat Dasar. Jakarta : Kwartir Nasional Gerakan Pramuka.

Mulyasa. 2013. Pengembangan dan Implementasi Kurikulum 2013. Bandung : PT Remaja Rosdakarya.

Undang-Undang Republik Indonesia Nomor 12 Tahun 2010 Tentang Gerakan Pramuka. 